\title{
La Caricatura y su uso didáctico en el estudio de la Primera Guerra Mundial
}

\author{
María Elena Del Valle de Villalba \\ Universidad Metropolitana de Caracas - Venezuela \\ mandelvalle@gmail.com
}

Recibido: 20 de agosto de 2013

Aceptado: 1 de octubre de 2013

\begin{abstract}
Resumen
El presente artículo pretende describir el uso que puede dársele a la caricatura como herramienta didáctica en el abordaje de la Primera Guerra Mundial como hecho histórico. En el mismo se describe de manera precisa la aplicación de esta herramienta como aporte a un abordaje transdisciplinario de la enseñanza de la Historia Universal y como una aproximación a la comprensión de un momento histórico tan sensible desde una perspectiva menos ortodoxa.
\end{abstract}

Palabras Clave: Caricatura; Historia Universal; Primera Guerra Mundial.

\section{The Cartoon and it's educational use in the study of the First World War}

\begin{abstract}
This article aims todescribe the usethat can be givento caricatureas a teaching toolin addressingthe FirstWorld Waras historical fact.Inthe sameaccuratelydescribesthe applicationof this toolas input toa transdisciplinary approachto teachingworld historyandas an approach tounderstanding ahistorical momentas sensitivefrom a lessorthodox.
\end{abstract}

Key Words: Cartoon; World History; World War.

\section{Referencia normalizada}

Del Valle de Villalba, M. E. (2013). La caricatura y su uso didáctico en el estudio de la Primera Guerra Mundial. Historia y Comunicación Social, vol. 18, páginas 75-85.

Sumario: 1. Introducción. 2. Breve historia de la caricatura. 3. Didáctica de la historia. 4. El caricaturista como pintor de la realidad. 5. Instrucciones para la aplicación de las caricaturas en el abordaje de la primera guerra mundial. 6. Caricaturas sugeridas. 7. Conclusiones y recomendaciones. 8.- Bibliografía

\section{"Caricatures are often the truest history of the times" Ralph Waldo Emerson}

\section{Introducción}

A la reconstrucción del pasado podemos llegar por varios caminos. Una de las más hermosas aventuras que emprenden los historiadores es la valoración de hechos históricos pretéritos a través de medios diversos. El desarrollo de la transdisciplina- 
riedad como reflexión necesaria ha abierto cercados antes incomunicados regalándonos la posibilidad de hacer audibles voces silenciadas. La Caricatura es uno de esos artefactos comunicacionales a través de los cuales podemos pulsar las inquietudes, las demandas y las denuncias de un determinado grupo humano. Desde antiguo el humor ha permitido decir en forma jocosa aquello que en espacios serios nos es imposible. De esta manera como Arlequín, a través de la presentación estereotipada de personajes y circunstancias nos permitimos decir, señalar y denunciar. Guzmán Urrero (2007:0), asevera que a través del tiempo la caricatura se ha empleado como medio de representación satírica de la realidad distorsionando los rasgos de personajes con fines humorísticos.

El trabajo de los caricaturistas gira entonces, en torno a destacar algunas debilidades y fortalezas, errores o aciertos del (os) personaje(s) retratado(s) dibujando de manera a veces poco obvia críticas necesarias. En el presente artículo nos proponemos realizar la descripción del uso didáctico que puede darse a la caricatura en el estudio de la Primera Guerra Mundial.

\section{Breve Historia de la Caricatura}

Partiendo del principio de que la caricatura es una representación más o menos exacta de la realidad, los orígenes de esta práctica deberían ser ubicados en el origen de la humanidad. Desde el momento en el que el hombre representa exagerando las características definitorias de algo o de alguien podríamos considerar que hace caricatura. Exageración de rasgos físicos, específicas fisionomías dibujadas al extremo, son los atributos más importantes de este singular artefacto. Honoré Daumier, era sin duda uno de los representantes más eximios de este género. Extraordinario crítico de sus tiempos, demostró que la imagen es mucho más que eso. Para 1832, y como parte de su participación en la revista Le Charivari, Daumier publicó su obra llamada "Gargantúa" (Gigante glotón y devorador insaciable, protagonista de la novela homónima de François Rabelais), en ella Louis- Philippe era cruelmente satirizado por Daumier, que destacaba especialmente la desagradable cabeza del monarca en forma de pera. Por este dibujo el artista fue multado y condenado a 6 meses de prisión en la Sainte-Pélagie. De esta manera, la caricatura cumplía su doble propósito, ser manifestación artística y a la vez radiografía social y política de los tiempos.

Otro grande de este arte es Toulouse Lautrec, quien no sólo se destacó en el dibujo y la pintura, sino que también pasó a la historia por lo elocuente de sus carteles. Azorín para 1913 afirmaba en torno al humorismo y su papel histórico que el divertimento espiritual es sumamente importante en la historia del desenvolvimiento humano; haciendo la historia de la ironía y del humor, tendríamos hecha la sensibilidad humana y consiguientemente la del progreso, la de la civilización (1913:51). La marcha de un pueblo está en la marcha de sus humoristas.Gombrich también apuntalaba esta opinión al señalar que el dibujante por desdeñable que sea su calidad 
artística, tienen más probabilidades de impresionar en una campaña de odio que el orador de masas y el periodista (1968:122).

Ya desde la antigüedad (con algunos detractores como Platón) la caricatura se nos presenta como un arma eficaz para comprender las realidades contextuales en clave profana e informal. En los tiempos llamados contemporáneos y de la mano de las señoritas de Avignon de Picasso, la metamorfosis de Kafka, La conjura de los necios, las esculturas de Giacometti, los cuadros de Francis Bacon, llegan a nosotros sus trazos todos ellos con el estilo mordaz y crítico que los caracteriza. ¿El denominador común? Un dibujo claro, diáfano, sin bandera o tal vez abrazado a alguna, de la realidad. Críticas mordaces a la política en la como diría Picasso, tal vez no te parezcas ahora... pero ya te parecerás.

En esta investigación se considerará caricatura a una pintura o dibujo que vendrá acompañada de algunas palabras cuyo propósito principal será la presentación satirizada de algún elemento de la realidad. La caricatura es definida por Barajas (2000) una de las técnicas básicas del dibujo de humor, perono la única; la esquematización, la antropomorfización, el pastiche, los juegos de imágenes y los procedimientos literarios son otros recursos del arsenal de la gráfica satírica. Además, mucho antes de la acunación del término ya existían la estética de lo grotesco, las ilustraciones humorísticas y las alegorías didácticas.

Bajtín (2003) y Gilles Lipovetsky (2002) establecen tres fases o momentos históricos de lo cómico en las representaciones:

- La primera, abordado por Bajtín, corresponde a la risa del realismo grotesco en el medioevo, fundada en la oposición entre la cultura oficial y la cultura popular. El realismo grotesco consiste en el rebajamiento del poder por medio de imágenes exageradas de la vida material y corporal.

- La segunda etapa se refiere a la era satírica, ubicada en la Edad Moderna y caracterizada por la agudeza y la ironía crítica puestas al servicio delo espiritual. Señala Villarreal (2013) que en nombre de la moralidad, los sujetos dejaron de reírse de sí mismos mientras que las celebraciones del humor pasaron de ser preferentemente públicas y colectivas para convertirse en actos restringidos al ámbito privado del individuo. Se promovió la disciplina corporal a través de modos de interiorización silenciosa que excluyeron al cuerpo, limitando la manifestación de exabruptos en público, como la carcajada.

- Finalmente, según el mismo autor, la tercera etapa corresponde a la sociedad humorística, que impera en la edad contemporánea. Los grabados protestantes se constituyeron en el inicio de la era satírica pero aprovecharon los recursos verbales e iconográficos desarrollados por la cultura popular en el medioevo. Posteriormente, las alegorías pasaron del movimiento protestante alemán al grabado practicado por los artistas de los Países Bajos durante los siglos XVI y XVII. 
Por su parte, Villarreal realiza una compacta síntesis de la evolución de la caricatura dentro de contextos eminentemente sociales e históricos resumiéndolo así:

La evolución de la caricatura pasa por las siguientes etapas:

1. La cultura popular de la risa, particularmente la estética del grotesco, tal como la plantea Bajtín (2003) en la Europa de la Edad Media y el Renacimiento.

2. La estrategia política durante la Reforma protestante en Alemania, que desarrolla la tradición del cartoon en panfletos ilustrados y carteles con el fin de movilizar al campesinado analfabeta.

3. La reacción contra el academicismo renacentista. En esta subversión se inscribe la obra de los hermanos Carracci, quienes en Bolonia acuñaron el término "caricatura" a fines del siglo XVI para referirse a la técnica desatirización fisonómica ( Barajas, 2009).

4. La ironía moralizante desarrollada entre los grabadistas de los Países Bajos en los siglos XVI y XVII (Barajas, 2009).

5. El desarrollo del capitalismo, la aparición del Estado-Nación y de la esfera pública burguesa en Inglaterra, Francia y Alemania.

6. El desarrollo de tecnologías de reproducción impresa.

7. El desarrollo del periodismo y la inserción en él de la práctica convencional de la caricatura política, y más tarde del cartón editorial, en Europa durante los siglos XVII, XVIII y XIX (p 98).

\section{Didáctica de la Historia}

Una vez realizado este exiguo paseo por el origen histórico de la caricatura, procedemos a hacer un dibujo también a vuelo de pájaro por las principales dificultades que enfrentan los maestros de Historia al pretender a veces infructuosamente llevar por el huerto de la Historia a sus estudiantes. Del Valle (2011:78) en este sentido señala que la función que la Historia como ciencia social está llamada a cumplir se ha visto vulnerada por la actual práctica educativa. Lejos de promover el sano cuestionamiento del pasado para generar la comprensión del presente, la enseñanza de la historia se ha convertido en la repetición de discursos académicos anónimos y poco profundos de fechas, lugares y nombres que no tienen beligerancia alguna en la vida de los estudiantes. Se vuelve una tarea agotadora aproximarse a la revisión de hechos históricos relevantes en la vida de la humanidad haciendo sólo uso de estrategias que en alguna medida son superadas por lo vertiginoso de los cambios y la inmediatez del conocimiento.

Enseñar Historia hoy, a jóvenes que reciben a través de las redes sociales imágenes elocuentes, crudas y contundentes de lo que de manera expedita ocurre en su mundo, harán oloroso a naftalina y mejor que cualquier somnífero, cualquier clase magistral. 
De esta manera, la caricatura como postal de los tiempos, se nos antoja un nicho interesante, innovador para la aproximación a la enseñanza de cualquier momento histórico, en este caso: La Primera Guerra Mundial.

En relación a lo expresado señala Hernández (2012):

El humor empleado en las caricaturas, rompe con los esquemas de la clase magistral dejando la monotonía a un lado, convirtiendo el aula de clase en un escenario agradable y propicio para debates sobre temas que se estén tratando en dicho momento, permitiendo el desarrollo de análisis críticos y complejos, generados en el consenso, que llevan a un entendimiento más amplio y más claro de los conceptos tratados en clase (p 56)

De esta manera, como lo señala la autora, el uso de la caricatura en el aula permite, no sólo aproximarse al hecho histórico desde otra perspectiva, sino también involucrar en ella a docentes y estudiantes. En este mismo orden de ideas puntualiza Hernández (2012) los siguientes argumentos en relación a la pertinencia del uso de la caricatura como herramienta educativa:

1. La pedagogía es un elemento dinámico que permite hacer uso de diferentes herramientas, que facilita al ser humano aprender de una manera divertida e interactiva.

2. El humor, es un simple distractor que esconde la realidad y no permite el aprendizaje, ni sustenta métodos de enseñanza.

3. La caricatura sensibiliza e incentiva la reflexión sobre la condición humana del profesional y su entorno.

4. El análisis de la caricatura como herramienta pedagógica depende del enfoque dado por el facilitador y su grupo de estudio (p 76).

De esta manera, el uso que se haga de la caricatura como bien señala la autora, será determinante para el logro de la comprensión de los procesos históricos estudiados.

Villarreal (2013) afirma que Norman Fairclough (2008) identifica tres dimensiones analíticas del discurso: el texto, la práctica discursiva y la práctica social. Para efectos de nuestro contexto, se considera que las prácticas relacionadas con la caricatura pueden analizarse buscando la comprensión de un hecho histórico en particular, a partir de tres modalidades:

1. Textual, referida al entramado de codificaciones que materializan e discurso, es resultado tanto de la serie de prácticas no discursivas como de las discursivas.

2. Discursiva, considerada como la serie de los procedimientos que se ocupan directamente en la producción de los discursos, o sea, de la enunciación. En el ámbito periodístico, este tipo de prácticas constituyen lógicas que suelen articular hipercodificaciones y desvíos retóricos que configuran el decir. 
3. No discursiva, correspondiente a la serie de los procedimientos que no están directamente relacionados con la producción discursiva. Pueden ser operaciones programadas institucionalmente o bien, jugadas vinculadas a las culturas populares y los movimientos sociales. En las prácticas no discursivas se articulan "esquemas de operaciones y de manipulaciones técnicas" (De Certeau, 2000 , p. 51), que constituyen una tensión permanente entre la sacralización y la profanación sin que intervenga necesariamente una dilucidación verbal, por lo que se refieren en primer lugar al hacer.

Todas las anteriores pueden ser abordadas como se especifica en líneas posteriores extrayendo de ellas el mayor potencial posible para la dinamización y profundización de la comprensión del hecho histórico seleccionado, en este caso la Primera Guerra Mundial.

\section{El Caricaturista como pintor de la realidad}

Para 1948 Lasswell establecerá algunas de las funciones que como pintores de la realidad cumplirán los caricaturistas, comunicadores sociales. Según Lasswell, los medios también actúan como centinelas cuando buscan detectar señales de peligro. Así, junto a la función de vigilancia social, tienen la obligación de ejercer la vigilancia doméstica proporcionando información acerca de la vida diaria. A estos dos tipos de vigilancia se debe agregar la vigilancia política, esto es, el control de los poderes públicos y gubernamentales. Según el mismo autor (1948:123) además de informar acerca de los asuntos políticos, de la sociedad y de la vida doméstica, también proporcionan explicaciones e interpretaciones para ayudar a los ciudadanos a comprender el significado de lo que se ha expresado a través de la caricatura. Por último y como función básica de la caricatura y del caricaturista esta tiene un carácter educativo. Esto es, la transmisión de la cultura de generación en generación, hacia otros grupos sociales y hacia fuera de las fronteras intentando dar lecciones en relación a lo que sucede en un momento determinado.

La denuncia de problemas socio-políticos, la evidencia de asimetrías sociales, la representación de grupos minoritarios, la visibilización de actores anulados por el contexto, todo esto hace del artista no sólo el dibujante de una pieza de arte, sino también el retratista de la realidad. La Historia como ciencia relata los hechos, en muchos casos desde la narrativa del ganador, es por esto que la caricatura puede aproximarnos a esa voz enmudecida por discursos elitescos.

La caricatura, afirma Briceño es un arte en el que, por escasas reglas y medios muy elementales, se expresa la vida, las costumbres y el pensamiento de una época o de un pueblo. Su más alto valor reside en descubrir cualidades ocultas pero decisivas de una persona o situación, provocando la sonrisa o la franca carcajada, como también creando reacciones de reflexión y análisis (2005:178). 


\section{Instrucciones para la aplicación de las caricaturas en el abordaje de la Primera Guerra Mundial}

Como se señalaba al principio de estas líneas, nuestro propósito es presentar una alternativa que permita la aproximación a la comprensión de la Primera Guerra Mundial como hecho histórico a través del uso de la caricatura, en tal sentido, procederemos ahora a describir la manera en la que esto puedo llevarse a cabo.

\section{1.- Primera tarea: Estudio del Contexto}

En este primer momento es necesaria la revisión en profundidad, apoyados en el manual escolar o el texto designado para la administración del curso, una primera aproximación a los principales antecedentes de la Primera Guerra, descripción prolija de los elementos contextuales que propiciaron el estallido del conflicto, situación de Europa, principales naciones constituidas y reclamando espacios económicos y políticos. Desarrollo y caracterización de conceptos base como: Imperialismo y Colonialismo son medulares en este apartado. Diferenciando antecedentes de causas, establecer con la ayuda de bibliografía especializada pero a la vez correspondiente con el nivel del estudiantado, aproximarse a las causas tanto coyunturales como estructurales que propiciaron el conflicto. La rivalidad entre las potencias europeas, la creación de las alianzas, el asesinato del Archiduque Francisco Fernando y su esposa en Sarajevo, entre otras. Se requiere la caracterización de los diferentes actores, como cabezas visibles de cada nación, referencias biográficas de cada uno, así como también nos parece pertinente el acompañamiento del estudio del conflicto apoyado por mapas en los que geográficamente se aprecie el impacto del mismo en la repartición del territorio. Por último, el análisis de las consecuencias de la Guerra en la configuración de un nuevo mapa de Europa, las duras condiciones establecidas en el Tratado de Versalles para el gran perdedor de la Guerra y la valoración de cómo estas pueden considerarse como el embrión de conflictos posteriores.

\subsection{Segundo: Conformación de los grupos y asignación de la caricatura}

Dependiendo del número de estudiantes se organizan grupos no mayor de 4 personas, y se le asigna una caricatura del corpus.

\subsection{Tercero: Leer la caricatura}

Una vez realizada esta necesaria preparación, el reto será analizar la caricatura en función de determinar: ¿Qué sucede en la imagen?, ¿Qué personajes aparecen en ella?, ¿Son lo que son? O ¿Representan otras cosas?, ¿Qué relación hay entre los elementos de la caricatura?, ¿Qué colores se usan en ella?, ¿Los colores tienen algún significado?, ¿Cuál es?, ¿Hay la representación de algún espacio físico en concreto?, ¿Cuál?, ¿Cómo se le representa?, ¿Dónde apareció esta caricatura?, ¿Quién es el autor?, ¿Qué carga ideológica tiene?, ¿Está a favor o en contra de alguno de los invo- 
lucrado?, ¿Qué símbolos hay en la caricatura?, ¿Hay rasgos de burla?, ¿Con quién?, ¿Qué elementos han sido exagerados?, ¿Qué intenta decir la exageración?

En este momento seguiremos los lineamientos de Rodríguez y Velásquez (2011) quienes proponen que para desarrollar este proceso, se da respuesta a las preguntas: quién, qué, dónde, cuándo y cómo, de acuerdo con los recursos semióticos que el autor de la caricatura presenta, como los títulos, la imagen y el texto de los globos; quién, se refiere al personaje o los personajes principales del tema propuesto en la caricatura; qué, hace relación al tema; dónde, indica el lugar donde se desarrollan los hechos; cuándo, corresponde al momento de la situación presentada, en la cual, la fecha de publicación de la caricatura da indicios de los hechos noticiosos respecto al tema que se presenta en la viñeta; y el cómo, describe el hecho en sí al que se refiere la caricatura. De este modo, se identifica y delimita el tema, el contexto y los personajes expuestos por el caricaturista en la viñeta; aspectos que permiten determinar los discursos y su interacción (p 42).

\subsection{Cuarto: Compilación y discusión}

Luego de haber analizado las caricaturas se procede a la discusión en la que cada grupo presenta la caricatura asignada y las valoraciones a las que llegaron, propiciando las aportaciones de los demás grupos. Como actividad de cierre, puede asignarse la búsqueda de otras caricaturas de otros conflictos bélicos tal vez más cercanos, geográficamente o emocionalmente a los estudiantes.

\section{Caricaturas sugeridas}

A continuación se compilan un conjunto de caricaturas que por su contenido tienen el potencial adecuado para la realización de la actividad:
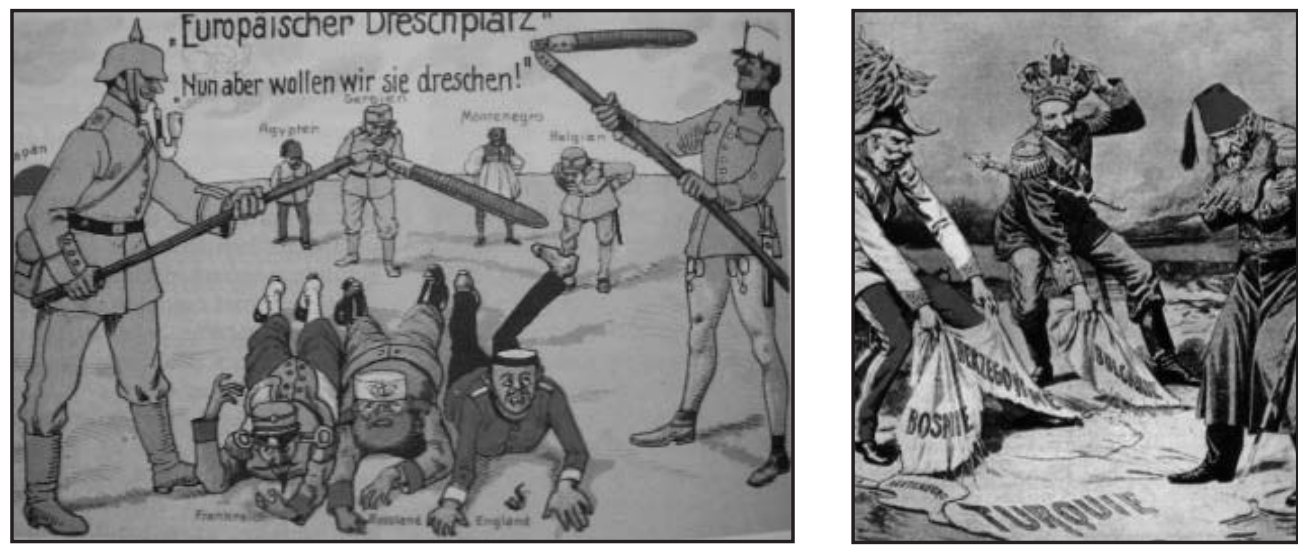

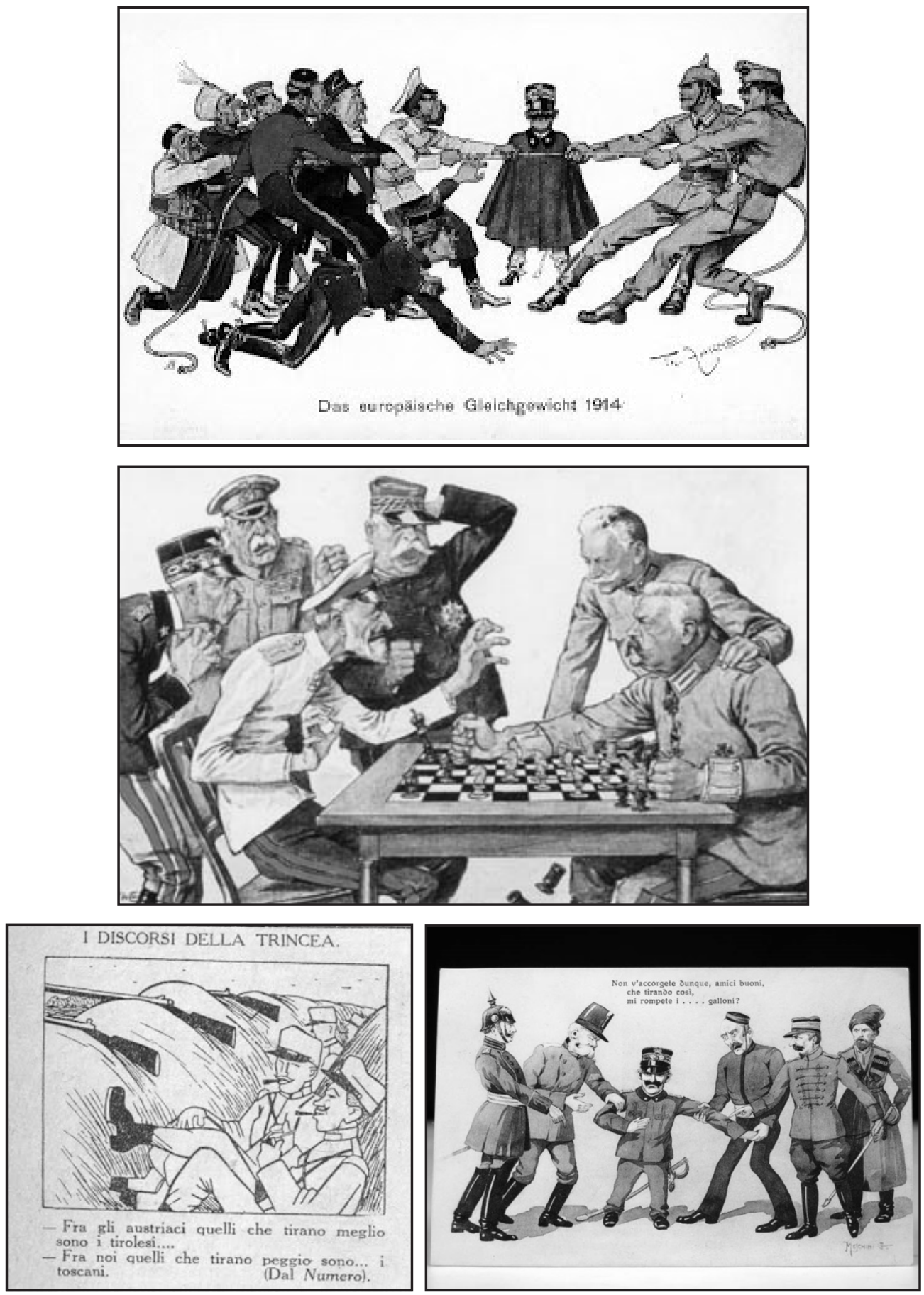


\section{Conclusiones y Recomendaciones}

Existen suficientes razones para usar la imagen encapsulada en la caricatura, como cierre de este muy breve artículo de enumeran algunas de ellas:

1. Se alcanza el objetivo que es el estudio de la Primera Guerra Mundial. Al culminar la actividad el estudiante habrá desarrollado las competencias de la gestión de información, habrá adquirido nuevo vocabulario y habrá desarrollado las destrezas comunicativas al expresarse oralmente en la discusión del tema y las caricaturas.

2. Se motiva al estudiante a través de una actividad que se sale de lo tradicional y se estimula la creatividad al analizar las implicaturas de la caricatura.

3. Se logra un alto nivel de comunicación en el aula, entre los estudiantes y entre ellos y el profesor.

4. Se transmiten elementos culturales de manera más directa y efectiva.

5. Se le aporta dinamismo a la enseñanza de contenidos tan medulares como los desarrollados en la Historia Universal y se contribuye a la aproximación a su comprensión.

\section{Bibliografía}

AZORÍN, (1913) Clásicos y modernos. Renacimiento: Madrid.

BAJTÍN, M. (2009). El problema de los géneros discursivos. En Estética de lacreación verbal. México: Siglo XXI editores

BARAJAS, R. (2009b). Sólo me río cuando me duele: La cultura del humor enMéxico. México: Planeta.

BARAJAS, R. (2000). La historia de un país en caricatura: Caricatura mexicanade combate (1829-1872). México: Consejo Nacional para la Cultura y lasArtes/Arte e Imagen.

BRICEÑO. C (2005) La prensa y la caricatura como...: Revista de Teoría y Didáctica de las Ciencias Sociales. Mérida-Venezuela. ISSN 1316-9505. Enero-Diciembre. $\mathrm{N}^{\mathrm{o}}$ 10: 175-183.

DE CERTEAU, M. (2000). La invención de lo cotidiano. I. Artes de hacer. México:Instituto Tecnológico de Estudios Superiores de Occidente A. C./Universidad Iberoamericana.

DEL VALLE, M (2011) Las Fórmulas docentes en la enseñanza de la Historia: Una revisión a sus efectos. Revista de Comunicación de la SEECI. (Marzo 2011). Año XIV (25), 60-68 ISSN: 1576-3420

GOMBRICH, E, (1968) Meditaciones sobre un caballo de juguete, Seix Barral,: Barcelona.

HERNÁNDEZ, D. (2012) La Caricatura como herramienta Pedagógica. Universidad Tecnológica de Pereira: Pereira. Colombia. 
LASSWELL, H. (1948) The structure and function of communication in society. EnBRYSON, L. (comp.). The communication of ideas. New York: Harper and Brothers.

LIPOVETSKY, G. (2002). La sociedad humorística. En La era del vacio: Ensayossobre el individualismo contemporáneo (pp. 136-172). España: Editorial Anagrama. RODRÍGUEZ, D y VELÁSQUEZ, A. (2011) Análisis Crítico del Discurso Multimodal en la Caricatura internacional. Cuadernos de Lingüística hispánica. Nro. 17. Bogotá. Colombia.

URRERO, G. (2007). Historia de la Caricatura, España. Disponible en: http://www. guzmanurrero.es/index.php/Comic/Historia-de-la-Caricatura.html. Extraído el 20 de Octubre de 2010.

VILLARROEL, C. (2013) Estrategias del género discursivo de la caricatura. Universidad Veracruzana: Veracruz. México.

\section{La autora}

María Elena Del Valle de Villalba es Doctora en Ciencias de la Educación en el Pedagógico de Caracas, Coordinadora del Núcleo de Investigaciones Geohistóricas Lisandro Alvarado, cuenta con proyectos financiados por la UPEL y con participación de la Universidad Complutense de Madrid, con proyectos financiados por el FONACIT, investigadora certificada de la Universidad Complutense de Madrid, el grupo internacional CONCILIUM y del CELARG, ponente regular en eventos nacionales e internacionales, adscrita a la línea de investigación, Ciencias del lenguaje y con siete años de investigación en el área de análisis del discurso. Profesora Ordinaria de la Universidad Pedagógica Libertador. Investigadora acreditada del CYTED, la AECID, profesora de la UNIMET con postdoctorado en semiótica y pragmática en la Universidad Complutense de Madrid. 